\title{
C-terminal in Sp1-like artificial zinc-finger proteins plays crucial roles in determining their DNA binding affinity
}

\author{
Baozhen Zhang ${ }^{\dagger}$, Shengyan Xiang ${ }^{\dagger}$, Yanru Yin, Liankun Gu and Dajun Deng ${ }^{*}$
}

\begin{abstract}
Background: It is well known that the C-terminal zinc-finger-3 in transcription factor Sp1 contributes more than the N-terminal zinc-finger-1 in determining Sp1's DNA binding capacity. Sp1-like artificial poly-zinc-finger proteins (ZFPs) are powerful biotechnological tools for gene-specific recognization and manipulation. It is important to understand whether the C-terminal fingers in the Sp1-like artificial ZFPs remain crucial for their DNA binding ability. Recently, a set of $p 16$ promoter-specific seven-ZFPs (7ZFPs) has been constructed to reactivate the expression of methylation-silenced p16. These 7ZFPs contain one N-terminal three-zinc-finger domain of Sp1 (3ZF), two Sp1-like two-zinc-finger domains derived from the Sp1 finger-2 and finger-3 (2ZF) in the middle and C-terminal regions.

Results: In the present study, sets of variants for several representative 7ZFPs with the p16-binding affinity were further constructed. This was accomplished through finger replacements and key amino acid mutations in the $\mathrm{N}$-terminal fingers, C-terminal fingers, and linker peptide, respectively. Their p16-binding activity was analysed using gel mobility shift assays. Results showed that the motif replacement or a key amino acid mutation $(S>R)$ at position +2 of the a-helix in the C-terminal 2ZF domain completely abolished their p16-binding affinity. Deletion of three amino acids in a consensus linker (TGEKP > TG) between finger-7 and the $6 \times$ Histidine-tag in the C-terminal also dramatically abolished their binding affinity. In contrast, the replacement of the finger-3 in the N-terminal 3ZF domain did not affect their binding affinity, but decreased their binding stability.

Conclusions: Altogether, the present study show that the C-terminal region may play crucial roles in determining the DNA binding affinity of Sp1-like artificial ZFPs.
\end{abstract}

\section{Background}

The $\mathrm{C} 2 \mathrm{H} 2$ zinc-finger is one of the most common DNA-binding motifs in eukaryotes. Each $\mathrm{C} 2 \mathrm{H} 2$ zinc-finger domain is a simple $\beta \beta \alpha$-fold peptide and consists of about 30 amino acid residues in length. Structure stability of this fold is achieved by hydrophobic interaction by chelating of a single zinc ion with the conserved cysteine and histidine residues [1]. Nucleic acid recognition of zinc-finger proteins (ZFPs) is achieved through key amino acid residues at positions $-1,+2,+3$, and +6 of the $\alpha$-helix in each finger, which typically bind with three adjacent bases (a triplet) [2,3]. A simple mode of DNA recognition by the

\footnotetext{
* Correspondence: dengdajun@bjmu.edu.cn

†Equal contributors

Key laboratory of Carcinogenesis and Translational Research (Ministry of
Education), Division of Etiology, Peking University Cancer Hospital \& Instit

Key laboratory of Carcinogenesis and Translational Research (Ministry of
Education), Division of Etiology, Peking University Cancer Hospital \& Institute, Beijing 100142, China
}

(c) 2013 Zhang et al.; licensee BioMed Central Ltd. This is an open access article distributed under the terms of the Creative Commons Attribution License (http://creativecommons.org/licenses/by/2.0), which permits unrestricted use, distribution, and reproduction in any medium, provided the original work is properly cited. designing proteins with novel sequence specificities. To achieve high binding specificity in the context of a large genome, longer arrays of zinc-fingers are required [4]. The ability of artificial ZFPs to target specific DNA sequences has led to the development of chimerical DNA modifying enzymes and transcription factors for specific genes [5-9]. This in turn has opened the possibility of using the engineered ZFP-based factors as novel human therapeutics. Compared with two recently established CRISPR and TALE technologies [10,11], the Sp1-like ZFP transcription factors may still be the best choice for gene transcription therapy because of their low antigenicity for human beings.

It has been reported that $C$-terminal finger- 2 and finger-3 in transcription factor $\mathrm{Sp} 1$ contribute more than $N$-terminal finger-1 when targeting GC-box DNA [12].

\section{Biomed Central}


Similar phenomenon has also been observed in Kaiso and other $\mathrm{C} 2 \mathrm{H} 2$ zinc-finger protein $[13,14]$. However, it is not well studied whether the $C$-terminal domain in artificial ZFPs is still a crucial determinant for their DNA binding affinity. In addition, amino acid at position +2 of the $\alpha$-helix in zinc fingers might interact with the $4^{\text {th }}$ DNA base on the opposite strand of the flanking triplet DNA target. This amino acid/base contact enables synergy between adjacent fingers in sequence-specific DNA recognition for natural ZFPs such as tramtrack, Zif268, and Sp1 [15-17]. It is not clear whether the amino acid at position +2 in artificial ZFPs plays a role in DNA recognition as well.

P16 ${ }^{\mathrm{INK} 4 \mathrm{~A}}$ (CDKN2A/MTS1) is a cell cycle regulator involved in inhibition of the $\mathrm{G} 1$ phase progression [18]. Methylation of $p 16 \mathrm{CpG}$ islands silences transcription of this gene epigenetically in many cancers [19]. p16 Methylation positively correlates with the risk of malignant transformation of human epithelial dysplasia [20,21]. In our recent work, a group of $p 16$-promoter specific seven zinc-finger proteins (7ZFPs) were designed and fused with the activator VP64 domain to construct $p 16$-specific artificial transcription factors (p16ATFs). These p16ATFs could re-activate expression of methylation-silenced p16 through demethylation of $\mathrm{CpG}$ islands around the transcription start site of this gene [22]. Each of these 7ZFPs is composed of three-zinc-finger domain of the natural Sp1 (3ZF) in the $N$-terminal, two Sp1-like two-zinc-finger mutants derived from the Sp1 finger-2 and -3 in the middle and $C$-terminal regions. In the present study, a set of $N$-terminal, $C$-terminal, and linker variants for the representative 7ZFPs with $p 16$-binding activity were further constructed, and used for comparison of contributions of different regions to the $p 16$-binding activity.

\section{Methods}

\section{Target p16 sequence, oligos, and probes}

It has been reported that $-622 \mathrm{nt} \sim-280 \mathrm{nt}$ region is the core promoter of $p 16$ gene and that the Sp1-binding site within $-466 n t \sim-451 \mathrm{nt}$ region (refer to the translation start site ATG) is crucial for transcription of this gene [23,24]. Thus, a 21 bp fragment within the core promoter (Figure 1a), including a natural Sp1-binding site (5'-ggggcgggg- $\left.3^{\prime}\right)$ and its $5^{\prime}$-flank 12 bp sequence ( $5^{\prime}$-gaggaaggaaac- $\left.3^{\prime}\right)$, was used as the target sequence to design $p 16$-specific binding proteins of artificial 7ZFPs in our recent study [22]. The $p 16$ promoter-specific sequence of the biotin-labelled and unlabelled double-strand DNA Probe- 1 used in electrophoresis mobility shift assay (EMSA) was $5^{\prime}$-aaggt tgtat cgcgg aggaa ggaaa cgggg cgggg gcgga tttct- 3 ' that contains the 21 bp 7ZFP binding site. A p16 5'UTR-specific sequence containing a postulated Sp1-binding site was used as the control probe (Probe-2: $5^{\prime}$-agggg ctggc tggtc accag agggt ggggc ggacc gagtg cgctc- $\left.3^{\prime}\right)$. These double-strand probes were purified by polyacrylamide gel (PAGE).

\section{Construction of 7ZFPs}

The designed $p 16$-specific 7ZFPs were constructed as described before [22]. Briefly, the two-zinc-finger modules (2ZF) derived from the Sp1 zinc-finger-2 and -3 were obtained by overlap-PCR using synthesized oligo deoxynucleotides containing the coding sequence of zinc-fingers, and then ligated together with the $N$-terminal 3ZF modules by particular restriction enzyme (Figure 1b). Furthermore, various $N$-terminal and $C$-terminal finger or linker variants were respectively constructed for the representative 7 ZFPs that could bind with the p16 promoter specifically using various oligos DNA (Figure 1c and Table 1). All of these 7ZFPs and their variants were inserted into T-cloning vector and confirmed by sequencing.

\section{Preparation of soluble 7ZFPs}

7ZFP-coding sequences in T-cloning vectors were digested by $\mathrm{NcoI}$ and $\mathrm{XhoI}$ restriction enzymes, and then inserted into six different kinds of expression vectors including pET-28a, pET-30a, pET-32a, pMal-p2X, pGEX-4 T-1, and pQE-Trisystem. These constructs were transformed into the corresponding expression bacteria and cultured in LB medium overnight. After the density of the culture was adjusted to $0.5 \mathrm{OD}_{600 \mathrm{~nm}}$ with the fresh medium, 7ZFPs expression was induced by addition of IPTG (Genview, USA) to the medium (final concentration, $0.1 \mathrm{mM}$ ) under different temperatures for different culture times. The sonicated bacteria proteins were separated by SDS-PAGE and visualized by Coomassie Blue staining. The amounts of soluble 7ZFPs from different expression vectors were compared with each other to select an optimal expression vector for preparation of the soluble ZFPs as described below.

After the IPTG-induction of expression of 7ZFPs in the above tested vectors, the bacteria were pelleted by centrifugation, and then frozen at $-80^{\circ} \mathrm{C}$ if necessary. The pellets were re-suspended in $2 \mathrm{ml}$ cold $\mathrm{PBS} / 0.1 \%$ NP-40 buffer per $10 \mathrm{ml}$ bacteria culture and lysed by ultrasonication followed by centrifugation (10000 rpm for $10 \mathrm{~min})$. The soluble 7ZFPs were purified from the sonicated supernatants through incubation with Ni-NTA-Sepharose beads (GE Healthcare, German) for $1 \mathrm{hr}$, and eluted from the beads with $500 \mathrm{mmol} / \mathrm{L}$ of imidazole, according to the protocol of the instruction manual. The purified proteins were subjected to electrophoresis and Western blot to confirm their size and purity.

\section{Western blot}

The proteins were electrophoresed through 12\% SDS-PAGE and then transferred onto PVDF membranes. After blocking with $5 \%$ fat-free milk overnight at $4^{\circ} \mathrm{C}$, the primary monoclonal antibody against $6 \times$ Histidine-tag (Beijing PuLiLai Company, China) were applied at 1:2000 dilutions for $1 \mathrm{hr}$ at room temperature. After 


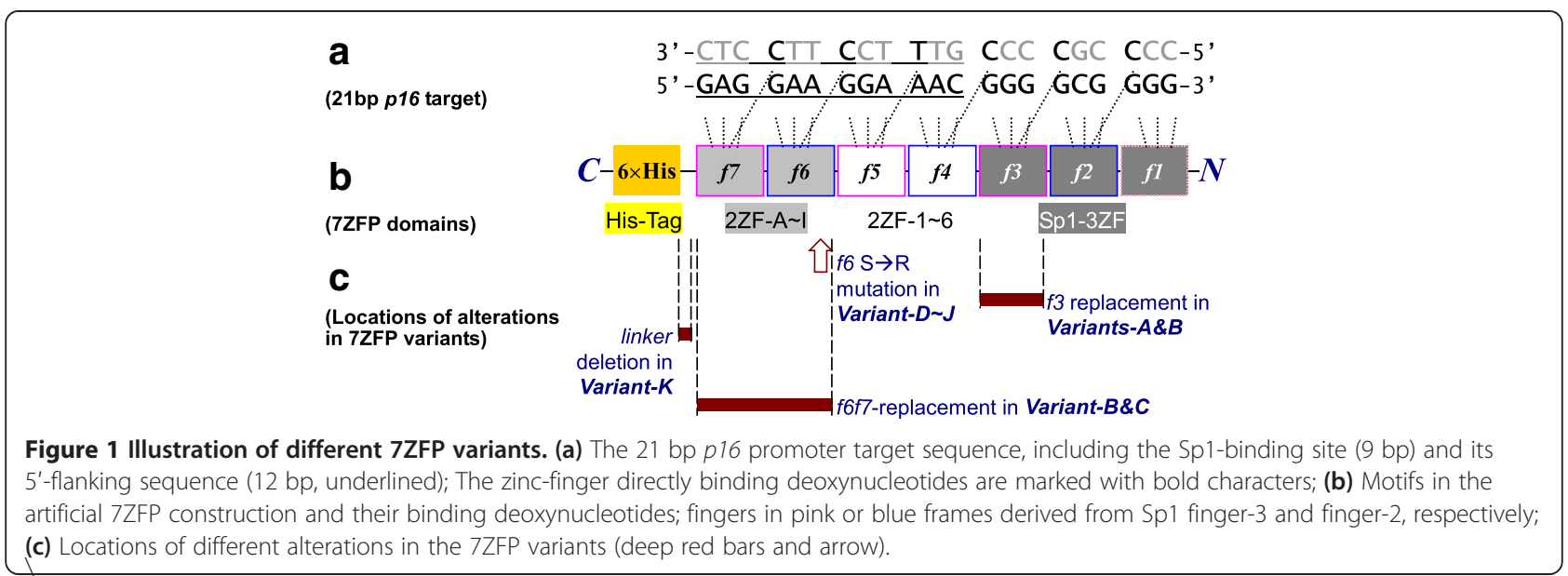

washing, the membrane was incubated with specific horseradish peroxidase-conjugated secondary antibody for $1 \mathrm{hr}$. The signals were visualized using the Enhanced Chemoluminescence kit (PIERCE, USA).

\section{Electrophoresis mobility shift assay (EMSA)}

Light Shift Chemiluminescent EMSA Kit (PIERCE, USA) was used. The EMSA assay was carried out according to the protocol of the Kit instruction as described previously [22]. Briefly, 5 nmoles of the biotin-labelled p16-promoter specific probes was incubated with $2 \mu \mathrm{l}$ of the tested protein for $30 \mathrm{~min}$ on ice in $1 \times$ binding buffer $(25 \mathrm{mM}$ HEPES, $100 \mathrm{mM} \mathrm{KCl}, 1 \mathrm{mM}$ EDTA, $10 \mathrm{mM} \mathrm{MgCl}$, 0.1\% NP40, 1\% glycerol, $1 \mathrm{mM}$ DTT). The reaction mixture were run on a $7 \%$ polyacrylamide/ $0.5 \times$ TBE gel containing $2.5 \%$ glycerol at $100 \mathrm{~V}$ for $80 \mathrm{~min}$ and then transferred onto Hybond $\mathrm{N}+$ nylon membrane (Amersham, USA). In the competition assay, 25-, 200-, and 400-fold excesses of the corresponding unlabeled probes were pre-incubated with the tested proteins for $30 \mathrm{~min}$ prior to the addition of the labelled probes.

\section{Results}

\section{Design and construction of 7ZFP variants}

To evaluate the contribution of each domain in active artificial ZFPs to DNA binding activity, sets of 7ZFPs variants containing key amino acid mutations, finger replacements, and linker deletion in the $C$-terminal and $N$-terminal regions were designed and constructed respectively for the representative 7ZFPs which strongly bind to the $p 16$ target DNA (Figure 1), according to our recently report [22]. These variants includes, [I] two kinds of finger-replacement mutants in the $N$-terminal $3 Z \mathrm{ZF}$ and $C$-terminal 2ZF domains [Table 1, lines $2 \sim 7$ : Variant- $A / B$ (f3) and Variant-B/C(f6f7)]; [II] two sets of mutants containing a $\mathrm{S}>\mathrm{R}$ amino acid mutation at position +2 of finger-6 in the $C$-terminal 2ZF domain (Table 1, lines $8 \sim 21$, Variant-D J); and [III] a linker mutant with a deletion of three amino acids (TGEKP> TG) between finger- 7 and $6 \times$ Histidine-tag in the $C$-terminal region (Table 1 , lines $22 \sim 23$, Variant-K).

\section{Optimisation of conditions for soluble 7ZFP preparation}

To obtain soluble 7ZFPs, two distinct representative 7ZFPs [Active- $H$ and Variant- $F(f 6)$ with the maximum number of amino acid differences] were inserted into six different kinds of expression vectors, including pET-28a, pET-30a, pET-32a, pMal-p2X, pGEX-4T-1, and pQE-Trisystem. Following transforming these vectors, the expression level and percentage of the soluble 7ZFPs in the corresponding bacteria were compared under various culture temperatures $\left(10^{\circ} \mathrm{C}, 17^{\circ} \mathrm{C}\right.$, and $\left.25^{\circ} \mathrm{C}\right)$ and IPTG induction times (12 hr and $24 \mathrm{hr}$ ). Results showed that soluble Active- $H$ was most efficiently expressed in the pET-28a vector-transfected Rosetta (DE3) bacteria, after treatment of $0.1 \mathrm{mM}$ of IPTG at $17^{\circ} \mathrm{C}$ for $24 \mathrm{hr}$ (Figure 2). Most 7ZFPs expressed in the pET-28a vector were dissolved in the sonicated supernatants (about $25 \mathrm{kD}$ ). Similar results were obtained for Variant-F(f6) (data not shown). Therefore, the pET-28a vector was used to express the soluble 7ZFPs for further experiments. After purification using Ni-NTA-Sepharose beads, the soluble 7ZFPs were detected as a marked specific band and confirmed by Western blot (Figure 3). Such a band was not observed in the uninduced or pET-28a transformed-control bacteria.

\section{Comparison of DNA binding affinity and specificity of 7ZFPs with their variants}

As previously reported [22], results in the EMSA assays using the purified 7ZFPs showed that the representative 7ZFPs including Active- $A$ to $-K$ had high affinity binding to the $p 16$ promoter-specific Probe-1 (Figures 4, 5, and Table 1). First, we investigated whether substitution of single amino acid mutation $(S>R)$ at position +2 of finger-6's $\alpha$-helix in the $C$-terminal $2 \mathrm{ZF}$ could affect the Probe-1 binding affinity. As shown in Figure 4a, 
Table 1 List of the target triplets, amino acid residues at the position $-1 \sim+6$ of the $a$-helix of each single-zinc-finger domain of active $7 Z$ FPs and their binding activity

\begin{tabular}{|c|c|c|c|c|c|c|c|c|c|}
\hline \multirow[t]{3}{*}{$\begin{array}{l}\text { Active 7ZFPs and their } \\
\text { variants marked with } \\
\text { the line number }\end{array}$} & \multirow[t]{3}{*}{$\begin{array}{c}\text { p16 DNA } \\
\text { binding activity }\end{array}$} & \multicolumn{3}{|c|}{$\begin{array}{l}N \text {-terminal } S p 1 \text { three-zinc-finger } \\
\text { domain ( } 3 Z F \text { ) and its mutants }\end{array}$} & \multicolumn{2}{|c|}{$\begin{array}{l}\text { Middle } S p 1 \text {-like two-zinc-finger } \\
\text { modules (2ZF) }\end{array}$} & \multicolumn{2}{|c|}{$\begin{array}{l}\text { C-terminal Sp1-like } \\
\text { two-zinc-finger } \\
\text { modules (2ZF) }\end{array}$} & \multirow[t]{3}{*}{$\begin{array}{l}\text { C-terminal linker } \\
\text { between finger-7 \& } \\
6 \times \text { His-tag }\end{array}$} \\
\hline & & finger-1 & finger-2 & finger-3 & finger-4 & finger-5 & finger-6 & finger-7 & \\
\hline & & $5^{\prime}-\mathrm{ggg}-3^{\prime}$ & $5^{\prime}-\mathrm{gcg}-3^{\prime}$ & 5'-ggg-3' & $5^{\prime}$-aac-3' & 5'-gga-3' & $5^{\prime}$-gaa-3' & 5'-gag-3' & \\
\hline \multicolumn{10}{|c|}{ - Finger motif replacement } \\
\hline 1 Active-A (consensus) ${ }^{b}$ & $(++)$ & KTSHLRA & RSDELQR & RSDHLSK & ESDNLSQ & QSGHLQR & QSSNLQR & RSDNLAR & TGEKP \\
\hline 2_Variant-A (f3) & $(++)$ & $-------{ }^{c}$ & ------- & $\mathrm{Q}-\mathrm{G}--\mathrm{QR}$ & -------- & ------- & ------- & ------- & ----- \\
\hline 3_Active-B & $(++)$ & -------- & -------- & -------- & -------- & -------- & -------- & $-----\mathrm{T}-$ & ----- \\
\hline 4_Variant-B (f3) & $(++)$ & ------- & ------- & $\mathrm{Q}-\mathrm{G}--\mathrm{QR}$ & ------- & ------- & ------- & $-----T-$ & ----- \\
\hline 5_Variant-B (f6f7) & $(-)$ & ------- & ------- & ------- & ------- & -------- & $\mathrm{D}-\mathrm{G}--\mathrm{R}-$ & $\mathrm{Q}-\mathrm{GH}-\mathrm{Q}-$ & ----- \\
\hline 6_Active-C & $(++)$ & ------- & ------- & ------- & ------- & $--\mathrm{T}----$ & ------- & $-----\mathrm{T}-$ & ----- \\
\hline 7_Variant-C (f6f7) & $(-)$ & ------- & ------- & ------- & ------- & $--\mathrm{T}----$ & $\mathrm{D}-\mathrm{G}--\mathrm{R}-$ & $\mathrm{Q}-\mathrm{GH}-\mathrm{Q}-$ & ----- \\
\hline \multicolumn{10}{|c|}{ - Single key amino acid mutation } \\
\hline 8_Active-D & $(+)$ & ------- & -------- & ------- & ------- & -------- & $-----V_{-}$ & $---\mathrm{A}-\mathrm{Q}-$ & ----- \\
\hline 9_Variant-D (f6) & $(-)$ & ---- & --- & ------- & ------- & ------- & $--\mathrm{R}--\mathrm{V}-$ & $---\mathrm{A}-\mathrm{Q}-$ & ----- \\
\hline 10_Active-F & $(++)$ & -------- & ---- & ------- & -------- & -- T---- & $-----V_{-}$ & $-----{ }_{-}$ & ----- \\
\hline 11_Variant $-F(f 6)^{d}$ & $(-)$ & ------- & ------- & ------- & ------- & $--\mathrm{T}----$ & $--R--V-$ & $-----{ }_{-}-$ & ----- \\
\hline 12_Active-G & $(++)$ & ----- & ---- & ------- & $\mathrm{D}-\mathrm{G}--\mathrm{RV}$ & -------- & $-----V_{-}$ & $-----\mathrm{T}-$ & ---- \\
\hline 13_Variant-G (f6) & $(-)$ & ------- & ----- & ------- & $\mathrm{D}-\mathrm{G}--\mathrm{RV}$ & ------- & $--R--V-$ & $-----\top-$ & ----- \\
\hline 14_Active- $H^{C}$ & $(+)$ & -------- & ---- & -------- & $\mathrm{D}-\mathrm{G}--\mathrm{RV}$ & -------- & $-----V_{-}$ & $---\mathrm{A}-\mathrm{Q}-$ & ----- \\
\hline 15_Variant-H (f6) & $(-)$ & ------ & --- & ---- & $\mathrm{D}-\mathrm{G}--\mathrm{RV}$ & -------- & $--\mathrm{R}--\mathrm{V}-$ & $---\mathrm{A}-\mathrm{Q}-$ & --- \\
\hline 16_Active-I & $(++)$ & ----- & & -------- & $\mathrm{D}-\mathrm{G}--\mathrm{RR}$ & -------- & $-----V_{-}$ & $-----T-$ & --- \\
\hline 17_Variant-I (f6) & $(-)$ & -------- & -------- & -------- & $\mathrm{D}-\mathrm{G}--\mathrm{RR}$ & -------- & $--R--V-$ & $-----\top-$ & ----- \\
\hline 18_Active-J & $(+)$ & -------- & -------- & -------- & $\mathrm{D}-\mathrm{G}--\mathrm{RR}$ & -- -T---- & $------V_{-}$ & $---\mathrm{A}-\mathrm{Q}-$ & ---- \\
\hline 19_Variant-J (f6) & $(-)$ & -------- & -------- & -------- & $\mathrm{D}-\mathrm{G}--\mathrm{RR}$ & $--\mathrm{T}-----$ & $--\mathrm{R}--\mathrm{V}-$ & $---\mathrm{A}-\mathrm{Q}-$ & ----- \\
\hline 20_Active-K & $(++)$ & ------- & -------- & -------- & $\mathrm{D}-\mathrm{G}--\mathrm{RR}$ & $--T----$ & $-----V_{-}$ & $-----T-$ & ----- \\
\hline 21_Variant-K (f6) & $(-)$ & -------- & -------- & -------- & $\mathrm{D}-\mathrm{G}--\mathrm{RR}$ & -- -T---- & $--R--V-$ & ----- T- & ----- \\
\hline \multicolumn{10}{|c|}{ - C-terminal linker deletion } \\
\hline 22_Active-K & $(++)$ & ------- & ------- & ------- & ------- & ------- & $-----V_{-}$ & $-----\mathrm{T}-$ & ----- \\
\hline 23_Variant-K (linker) & $(-)$ & -------- & ------- & ------- & -------- & ------- & $-----V_{-}$ & $-----\top-$ & TG \\
\hline
\end{tabular}

\section{3_Variant-K (linker)}

analyzed in EMSA assays.

the exact sequence of amino acids of 7ZFP ACtive-A: N-MASRDPGKKKQHICHIQGCGKVYGKTSHLRAHLRWHTGERPFMCTWSYCGKRFTRSDELQRHKRTHTGEKKFACPECPKRFMRSDHLSKHIKTHQTGEKPFMCTWSYCGKRFTESDNNLSQ HKRTHTGKKFACPECPKRFMQSGHLQRHIKTHTGEKPFMCTWSYCGKRFTQSSNLQRHKRTHTGEKKFACPECPKRFMRSDNLARHIKTHTGEKPFLEHHHHHH-C.

'the symbol "-" means the amino acid residue is the same as that in the consensus sequence of Active-A at the same position in the same column. 'used in optimization assays for soluble 7ZFP preparation. 


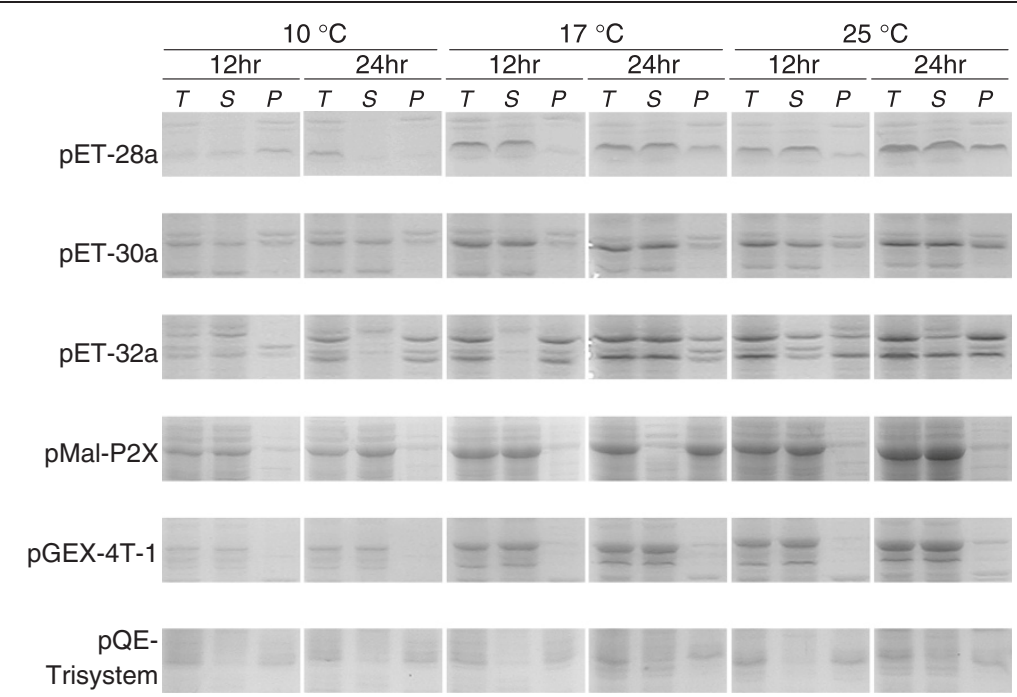

Figure 2 Comparison of the expression states of the soluble 7ZFP Active-H in various kinds of vectors under different culture temperatures and IPTG-induction times ( $T$ : whole bacteria; $S$ : the supernatant; $P$ : precipitate).

compared with Active-G and Active-I, this substitution completely abolished their binding ability with Probe-1 (compare lane 2 and 3, lane 4 and 5, also see Table 1, line 12 to 13 and line 16 to 17). The EMSA experiments with 7ZFPs Active-D, $F, H, J, K$ and their variants also showed the same results (EMSA image not shown, and Table 1, line 8 to 11 , line 14 to 15 , and line 18 to 21). Second, for 7ZFP Active-K, a deletion (TGEKP > TG) of 3 amino acid residues in the linker between $C$-terminal finger- 7 and the

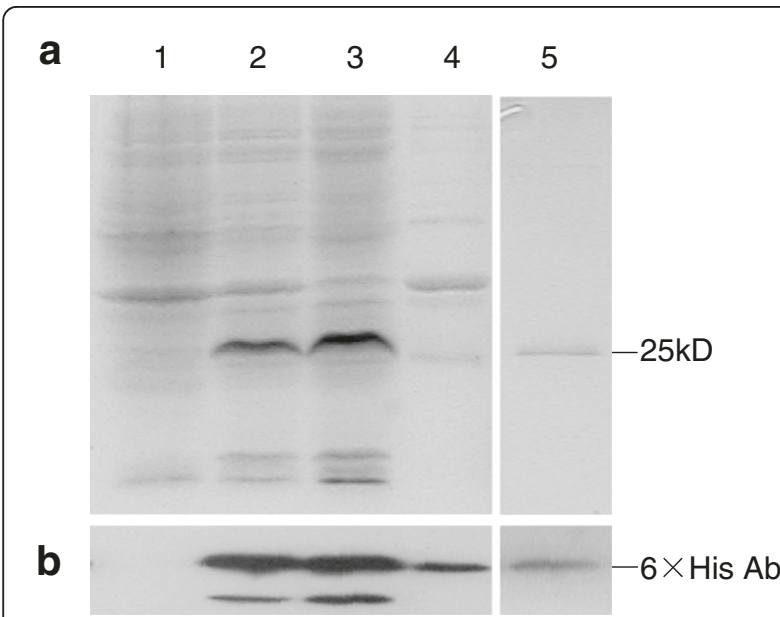

Figure 3 Total protein and purified 7ZFP Active- $H$ in different preparations from Rosetta DE3 bacteria transformed with the pET-28 7ZFP or empty control vectors. (a) Total crude proteins expressing 7ZFP (line-pointed band), Coomassie Blue staining. (b) The expression of 7ZFP Active-D was displayed in Western blot assay using antibody against $6 \times$ Histidine-tag (Lane-1, total protein for pET-28a control vector; Lane-2, total protein for pET-28a-7ZFP vector; Lane-3, the sonicated supernatant for pET-28a-7ZFP vector; Lane-4, the sonicated precipitate for pET-28a-7ZFP vector; Lane-5, 7ZFP purified from the sonicated supernatant using Ni-NTA-Sepharose beads).
$6 \times$ Histidine-tag also fully destroyed $p 16$ binding (Figure 4b, compare lane 6 and 7, Table 1, line 22 and 23). Next, full depletion of $p 16$ binding activity was also observed for the representative 7ZFPs Active- $B$ and Active- $C$ after their finger -6 and -7 were replaced with finger- 4 and -5 (Figure $4 \mathrm{~b}$, compare lane 2 and 3, lane 4 and 5; Table 1, compare line 3 and 5 , line 6 and 7). In contrast, the replacement of finger-3 at the $N$-terminal 3ZF domain with finger-5 in 7ZFPs Active- $A$ and Active- $B$ did not affect their $p 16$ binding affinity (Figure $5 \mathrm{a}$, compare lane 2 and 6; Figure 5b, compare lane 2 and 6; Table 1, compare line 1 and 2, line 3 and 4). These results suggest that the $C$-terminal fingers and flanking sequence may play a crucial role in determining the 7ZFPs' DNA binding affinity.

Competition EMSA assays using unlabeled Probe-1 and Probe- 2 were further carried out to investigate whether the $\mathrm{N}$-terminal domain in 7ZFPs contributes to the p16-binding specificity. Results showed that pre-incubation with the unlabeled $p 16$ promoter-specific Probe-1 $(25 \times)$ completely blocked the binding of both 7ZFPs Variant- $A(f 3)$ and Variant- $B(f 3)$ to Probe- 1 (Figure 5a, compare lane 6 and 7; Figure 5b, compare lane 6 and 7), but only partially decreased the binding of their active counterparts Active- $A$ and Active- $B$ to Probe-1 (Figure 5a, compare lane 2 and 3; Figure 5b, compare lane 2 and 3). Moreover, the pre-incubation with the unlabeled Probe-2 (a p16 5'UTR sequence containing a Sp1 binding site) did not decrease the DNA binding activity of 7ZFPs Active- $A$, Active- $B$ (Figure $5 \mathrm{a}$, lane 5 and Figure $5 \mathrm{~b}$, lane 5), nor their $N$-terminal 3ZF-variants Variant- $A(f 3)$ and Variant- $B(f 3)$ (Figure 5a, lane 9 and Figure 5b, lane 9). These results imply that 7ZFP $N$-terminal variants can specifically bind to the $p 16$ promoter target sequence with a decreased binding stability. 


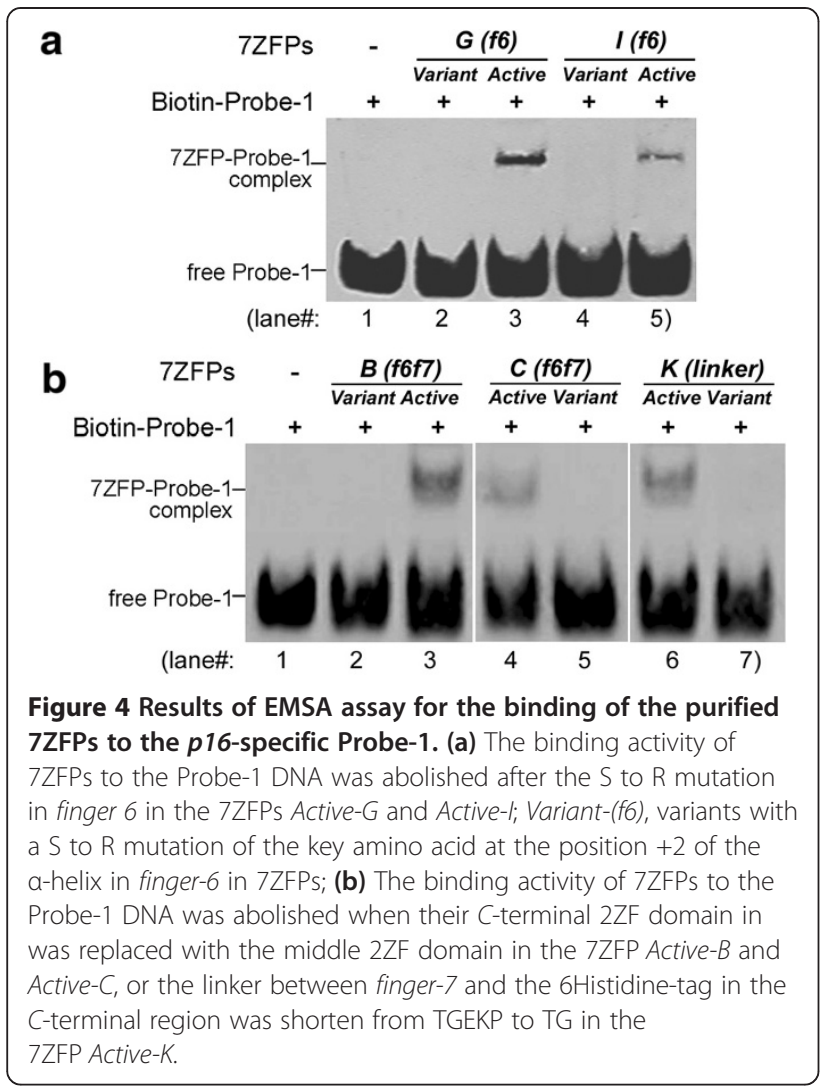

\section{Discussions}

The engineered DNA-binding proteins can be utilized to carry out a variety of cellular activities by combining them with different functional domains. Researchers have successfully designed novel nucleases and transcription factors using the $\mathrm{C} 2 \mathrm{H} 2$-type zinc finger domain as a scaffold [5-9]. However, the general principles of which zinc finger or which key amino acid in the engineered ZFPs play more important roles in the target binding are not well studied, especially for those containing multiple zinc fingers. In the present study, we found that the $C$-terminal region (finger and linker) in the artificial ZFPs played a more important role than the $N$-terminal region in determining their DNA binding affinity, and that the $N$-terminal fingers could stabilize their binding to the target DNA. Similar phenomena have previously been reported for several natural ZFPs [12-14]. However, to the best of our knowledge, this is the first report to show the functional difference between the $\mathrm{N}$-terminal and $\mathrm{C}$-terminal regions within the engineered ZFPs. These findings may be useful for ZFP engineering.

$\mathrm{Sp} 1$ is an important transcription factor that binds to several thousands of GC-boxes with the consensus sequence 5 '-GGGGCGGGG-3' in the genome. It is an ideal scaffold for adding more zinc-fingers to its three-zinc-finger domain and obtaining better gene-specificity for the engineered

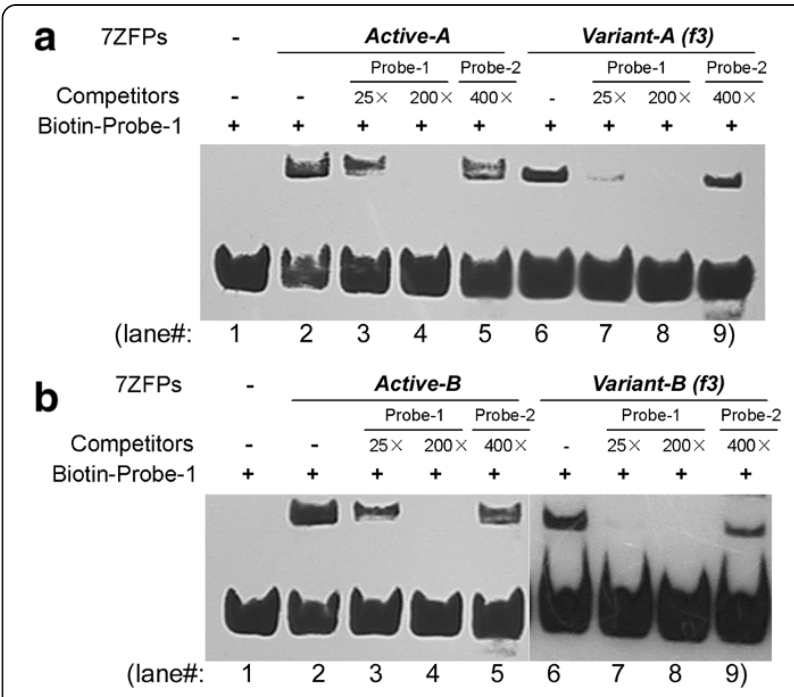

Figure 5 Regular and competition EMSA assays for the binding of the purified 7ZFPs to the $p 16$ promoter specific Probe- 1 . ( $\mathbf{a}$ and $\mathbf{b}$ ) The binding activity of 7ZFPs to the Probe-1 DNA was partially abolished after finger 3 (RSDHLSK) in the 7ZFPs Active-A and Active- $B$ was replaced with finger-5 (QSGHLQR). Probe- 2 is the fragment of p16 $5^{\prime} \mathrm{UTR}$ region containing a postulated Sp1 binding site.

transcription factors because of its accessibility to GC-boxes within chromatin and low antigenicity. It has been reported that contribution of the $C$-terminal finger-3 in natural $\mathrm{C} 2 \mathrm{H} 2$ ZFPs to their DNA-binding affinity is higher than the $N$-terminal fingers- 1 , and further that finger-1 can stabilize their DNA-binding [12-14]. In our study, $C$-terminal finger 3-in the natural Sp1 was used to construct 7ZFPs at its $\mathrm{N}$-terminal. Interestingly, after the 7ZFP finger-3 [RSDHLSK] in 7ZFPs Active- $A$ and Active- $B$ was replaced with the finger-5 [QSGHLQR], these 7ZFP variants showed the same DNA binding affinity; however, their DNA binding stability was decreased. These results indicate that the functions of finger-3 are changed after its location shifts from $C$-terminal in Sp1 to $N$-terminal in 7ZFPs. As in the natural Sp1, the $\mathrm{N}$-terminal fingers in the Sp1-like artificial ZFPs may play additional roles in stabilization of their DNA binding and few roles in determining their DNA binding affinity.

Studies on Zif268 and artificial ZFPs have suggested that the amino acid at position +2 of the $\alpha$-helix of each finger might be able to interact with the $4^{\text {th }}$ DNA base on the opposite strand of the flanking triplet DNA target, leading to synergy between adjacent fingers and enhancing specificity of the amino acids at other positions $[15-17,25]$. Amino acids with shorter and smaller side chains in artificial ZFPs are generally used for recognition of the $2^{\text {nd }}$ and $4^{\text {th }}$ DNA bases in artificial ZPF design [26]. Aspartic acid [D] and serine [S] exist frequently at position +2 of each $\alpha$-helix in zinc-fingers. In order to investigate whether the $C$-terminal fingers in the Sp1-like artificial ZFPs remain 
important for the DNA-protein binding as observed in the natural Sp1, C-terminal 2ZF variants containing the key amino acid mutation [from serine (with a polar but un-charged short side chain) to arginine (with a charged long side chain), $\mathrm{S}>\mathrm{R}$ ] at position +2 of the $\alpha$-helix in the finger-6, or whole 2ZF domain replacement (from the $C$-terminal 2ZF to the middle 2ZF) were constructed and used for evaluation of DNA binding affinity changes in EMSA assay. As expected, both the $\mathrm{S}>\mathrm{R}$ mutation and $C$-terminal 2ZF replacement completely impaired the affinity of their corresponding 7ZFPs. These results show that the $C$-terminal domain in the Sp1-like artificial ZFPs remains important in determining the DNA binding affinity, as observed in the natural Sp1.

It has been reported that Kaiso uses all three fingers as well as the flanking sequences for high-affinity binding to target DNA and that extended linker may be helpful for the DNA binding of ZFPs [14,27]. In the present study, it was found that deletion of three amino acid residues in the linker between the $C$-terminal finger- 7 and $6 \times$ Histidine-tag also completely abolished the binding affinity of 7ZFPs to $p 16$ promoter-specific DNA. This suggests that the proper flexibility of the adjacent amino acid sequence flanking the $C$-terminal fingers is also a determinant for the high DNA binding affinity of the Sp1-like ZFPs.

\section{Conclusions}

The present study show for the first time that the $C$-terminal domain in the Sp1-like artificial ZFPs may play a crucial role in determining ZFPs' binding affinity to the target DNA and that the $N$-terminal domain may help stabilizing this binding affinity.

\section{Competing interests}

The authors declare that they have no competing interests.

\section{Authors' contributions}

BZ constructed the ZFP variants and performed the competition EMSA assays with the purified ZFPs and drafted the manuscript. SX designed the zinc-finger units and constructed the 7ZFPs vectors. YY performed the regular EMSA experiments. LG participated in the preparation and purification of 7ZFPs. DD conceived of the study and revised the manuscript. All authors read and approved the final manuscript.

\section{Acknowledgments}

We thank Dr. Kendra A. Williams at University of South Florida for English language editing.

\section{Funding}

The present work was supported by National Basic Research Program of China [Grant No. 2011CB5504201] and by National Natural Science Foundation of China [Grant No. 30471996, 30701000, and 30873016].

Received: 26 June 2013 Accepted: 25 November 2013 Published: 1 December 2013

\section{References}

1. Diakun GP, Fairall L, Klug A: EXAFS study of the zinc-binding sites in the protein transcription factor IIIA. Nature 1986, 324:698-699.
2. Pavletich NP, Pabo CO: Zinc finger-DNA recognition: crystal structure of a Zif268-DNA complex at 2.1 A. Science 1991, 252:809-817.

3. Elrod-Erickson M, Rould MA, Nekludova L, Pabo CO: Zif268 protein-DNA complex refined at 1.6 A: a model system for understanding zinc finger-DNA interactions. Structure 1996, 4:1171-1180.

4. Moore M, Klug A, Choo Y: Improved DNA binding specificity from poly zinc finger peptides by using strings of two-finger units. Proc Natl Acad Sci U S A 2001, 98:1437-1441.

5. Kim JS, Lee HJ, Carroll D: Genome editing with modularly assembled zinc-finger nucleases. Nat Methods 2010, 7(2):91.

6. Wilson KA, Chateau ML, Porteus MH: Design and development of artificial zinc finger transcription factors and zinc finger nucleases to the hTERT Locus. Mol Ther Nucleic Acids 2013, 2:e87.

7. Kang YA, Shin HC, Yoo JY, Kim JH, Kim JS, Yun CO: Novel cancer antiangiotherapy using the VEGF promoter-targeted artificial zinc-finger protein and oncolytic adenovirus. Mol Ther 2008, 16(6):1033-1040.

8. Stolzenburg S, Rots MG, Beltran AS, Rivenbark AG, Yuan X, Qian H, Strahl BD, Blancafort $\mathrm{P}$ : Targeted silencing of the oncogenic transcription factor SOX2 in breast cancer. Nucleic Acids Res 2012, 40(14):6725-6740.

9. Beltran A, Parikh S, Liu Y, Cuevas BD, Johnson GL, Futscher BW, Blancafort P: Re-activation of a dormant tumor suppressor gene maspin by designed transcription factors. Oncogene 2007, 26:2791-2798.

10. Qi LS, et al: Repurposing CRISPR as an RNA-Guided platform for sequence-specific control of gene expression. Cell 2013, 152:1173-1183.

11. Miller JC, et al: A TALE nuclease architecture for efficient genome editing. Nat Biotechnol 2011, 29:143-148.

12. Yokono $\mathrm{M}$, et al: Unique DNA binding mode of the N-Terminal Zinc Finger of Transcription Factor Sp1. Biochemistry 1998, 37:6824-6832.

13. Buck-Koehntop BA, Martinez-Yamout MA, Dyson HJ, Wright PE: Kaiso uses all three zinc fingers and adjacent sequence motifs for high affinity binding to sequence-specific and methyl-CpG DNA targets. FEBS Lett 2012, 586:734-739.

14. Nunez N, Clifton MM, Funnell AP, Artuz C, Hallal S, Quinlan KG, Font J, Vandevenne M, Setiyaputra S, Pearson RC, Mackay JP, Crossley M: The multi-zinc finger protein ZNF217 contacts DNA through a two-finger domain. J Biol Chem 2011, 286:38190-38201.

15. Fairall L, Schwabe JW, Chapman L, Finch JT, Rhodes D: The crystal structure of a two zinc-finger peptide reveals an extension to the rules for zinc-finger/DNA recognition. Nature 1993, 366:483-487.

16. Isalan $M$, Choo Y, Klug A: Synergy between adjacent zinc fingers in sequence-specific DNA recognition. Proc Natl Acad Sci U S A 1997, 94:5617-5621.

17. Isalan M, Klug A, Choo Y: Comprehensive DNA recognition through concerted interactions from adjacent zinc fingers. Biochemistry 1998, 37:12026-12033.

18. Serrano M, Hannon GJ, Beach D: A new regulatory motif in cell-cycle control causing specific inhibition of cyclinD/CDK4. Nature 1993, 366:704-707.

19. Merlo A, Herman JG, Mao L, Lee DJ, Gabrielson E, Burger PC, Baylin SB, Sidransky D: $5^{\prime} \mathrm{CpG}$ island methylation is associated with transcriptional silencing of the tumor suppressor p16/CDKN2/MTS1 in human cancer. Nat Med 1995, 1:686-692.

20. Sun Y, Deng DJ, You WC, Bai H, Zhang L, Zhou J, Shen L, Ma JL, Xie YQ, $\mathrm{Li} J \mathrm{JY}$ : Methylation of $\mathrm{p} 16 \mathrm{CpG}$ islands associated with malignant transformation of gastric dysplasia in a population-based study. Clin Cancer Res 2004, 10:5087-5093.

21. Cao J, Zhou J, Gao Y, Gu LK, Meng H, Liu HW, Deng DJ: Methylation of p16 CpG island associated with malignant progression of oral epithelial dysplasia: a prospective cohort study. Clin Cancer Res 2009, 15:5178-5183.

22. Zhang BZ, Xiang SY, Zhong QM, Yin YR, Gu LK, Deng DJ: The p16-Specific reactivation and inhibition of cell migration through demethylation of CpG islands by engineered transcription factors. Hum Gene Ther 2012, 23:1071-1081.

23. Wang $\mathrm{W}, \mathrm{Wu}$ J, Zhang Z, Tong T: Characterization of regulatory elements on the promoter region of p16ink4a that contribute to overexpression of p16 in senescent fibroblasts. J Biol Chem 2001, 276:48655-48661.

24. Wu J, Xue L, Weng M, Sun Y, Zhang Z, Wang W, Tong T: Sp1 essential for p16INK4a expression in human diploid fibroblasts during senescence. PloS One 2007, 2:e164. 
25. Choo $Y$, Klug A: Selection of DNA binding sites for zinc fingers using rationally randomized DNA reveals coded interactions. Proc Natl Acad Sci U S A 1994, 91:11168-11172.

26. Sera T, Uranga C: Rational design of artificial zinc-finger proteins using a nondegenerate recognition code table. Biochemistry 2002, 41:7074-7081.

27. Zhang BZ, Gu LK, Deng DJ: Mehtylation specific binding activity of zinc finger protein Kaiso. ZhongHua Yu Fang Yi Xue Za Zhi 2007, 41:43-46.

doi:10.1186/1472-6750-13-106

Cite this article as: Zhang et al:: C-terminal in Sp1-like artificial zinc-finger proteins plays crucial roles in determining their DNA binding affinity. BMC Biotechnology 2013 13:106.

\section{Submit your next manuscript to BioMed Central and take full advantage of:}

- Convenient online submission

- Thorough peer review

- No space constraints or color figure charges

- Immediate publication on acceptance

- Inclusion in PubMed, CAS, Scopus and Google Scholar

- Research which is freely available for redistribution 